\title{
Optics
}

\section{AFM studies of the effect of chloride ion on the morphology of the copper electroplating surface}

\author{
Masoud Delgosha $^{1}$, Samira Salehi $^{1}$, Leila Unesi borujeni ${ }^{2}$, Soheil Sharifi ${ }^{3}$ \\ ${ }^{1}$ Department of Physics, University of Sistan and Baluchestan, 98135-674 Zahedan, Iran \\ ${ }^{2}$ Department of physics, ShahidRajaee Teacher Training University, Lavizan, Tehran 16788-15811,Iran \\ ${ }^{3}$ Department of Physics, Faculty of Sciences, Ferdowsi University of Mashhad, Mashhad 91775-1436, Iran
}

Email address:

Delgosha.masoud@gmail.com (M. delgosha),heyhat2006@yahoo.com (M. delgosha)

\section{To cite this article:}

Masoud Delgosha, Samira Salehi, Leila Unesi borujeni, Soheil Sharifi. AFM Studies of the Effect of Chloride Ion on the Morphology of the Copper Electroplating Surface. Optics. Vol. 3, No. 2, 2014, pp. 15-18. doi: 10.11648/j.optics.20140302.12

\begin{abstract}
The influence of plating mode, chloride ion on morphology of copper deposits has been studied on pure copper substrate. The electroplating was conducted at $50 \frac{\mathrm{mA}}{\mathrm{cm}^{2}}, 25^{\circ} \mathrm{C}$ in cupric sulfate-sulfuric acid bath with various chloride additions 0.001-0.01 ml. The morphology and grain sizes of the electrodeposited copper were examined by atomic force microscopy. The maximum surface roughness and grain sizes of copper deposit were obtained when it was deposited with $0.01 \mathrm{ml}$ of chloride ions. Small particles were observed on the surface of the copper film electroplated with the addition of chloride ions up to the amount of $0.001 \mathrm{ml}$.
\end{abstract}

Keywords: Optic, DC Plating, Copper, Morphology, AFM

\section{Introduction}

Chemical vapor deposition (CVD), physical vapor deposition (PVD), sputtering, and electrodeposition methods have been used to many applications of copper plating which were developed for electronic device and through-hole plating for PCBs as well as conventional decorative plating on steel, electroforming, etc. Among these methods, electroplating is the most commercially important process because of its time efficiency, cost effectiveness, and absence of a vacuum system, which is required for the other processes. It also enables changes in the electrolyte composition rates, grain size, and deposition layer thicknesses by allowing variations in the deposition rate and time in response to the deposition potential[1,3].

Typically, dull copper deposits are produced by DC plating in sulphate-plating baths. There are two ways to improve their quality by the use of pulse plating and the inclusion of additives in the plating bath. Deposit properties (i.e., brightness, smoothness and microhardness) can also be improved through the inclusion of additives in a sulphate-plating bath. Both electrocrystallization and deposition kinetics are strongly sensitive to the presence of additives in the plating bath at very low concentrations. Typically, they influence deposit morphology and structure by adsorbing on the cathode and inhibiting various processes during electrodeposition [4].

It is well known that adding chloride ions in a sulfuric acid bath for copper electroplating is required to improve the surface brightness and mechanical properties of the deposit [5].The chloride ion, in bright and high-throw acid sulfate solutions, reduces anode polarization and eliminates striated deposits in high-current-density areas [6,7]. The chloride ion, in acid sulfate solutions, reduces anode polarization and eliminates striated deposits in highcurrent-density areas. The chloride ion affects the surface appearance, structure, microhardness, crystallographic orientation, and internal stress of the deposits. A minimal amount of chloride was essential to the ductility of deposits from two different proprietary copper plating solutions. Small amounts of chloride ion are known to have an accelerating effect on the deposition of copper. Excess chloride can produce insoluble copper chlorides at the anode surface, and hindering the deposition process [8].

However, few studies have focused on the microstructures of the cupreous chloride and/or the salt film formations. Some studies have reported that the crystallographic orientation and surface morphology of the copper deposit could be affected by chloride ion addition in the plating bath. It was also recognized that the smaller 
grain size of the copper deposit could be obtained with an addition of chloride ions. Carneval suggested that the anion could be a complex former or even posit with $\mathrm{Cu} 2+$ during copper deposition. However, changes in the microstructure and the electrocrystallization behavior of the copper deposit relating with the chloride addition were not examined and discussed in the previous literature [5]. Also, the addition of chloride ions dramatically reduces the size of the copper branches in the walls of holes. The reduction of pore size is a result of lowering hydrophobic force of the generated hydrogen gas by adding bubble stabilizer (e.g., acetic acid) that suppresses the coalescence of bubbles, while the decrease of branch size in the foam wall is a consequence of the catalytic effect of chloride ions on the copper deposition reaction [9].

The atomic force microscope (AFM) system has been evolved into a useful tool for direct measurements of intermolecular forces with atomic-resolution. AFMs do not require a vacuum environment and any special sample preparation, and they can be used in an ambient as well as liquid environment. The sample was probe and measured in three dimensions, $x, y$, and $z$ by AFMs (normal to the sample surface), thus provides the possibility of the presentation of three-dimensional images of a sample surface. By having these advantages, AFM has significantly affected the fields of materials science, chemistry, biology, physics, and also the specialized field of semiconductors $[10,11]$.

In relative to other microscopic methods (e.g. scanning electron microscopy (SEM) and transmission electron microscopy (TEM)), AFM provides more functionality and benefits in the studies of metallic surfaces and microstructures by providing reliable measurements at the nanometer scale [10]. With different cathodic substrates and additives, many studies have investigated the growth behavior of the copper deposit with an atomic force microscope AFM, by which the initial growth morphology and grain sizes of the deposit could be examined in the atomic scale.

In this study, we investigate the effects of plating mode and the additives chloride on the morphology of copper electrodeposits.

\section{Experimental}

The copper electroplating was performed in a conventional acid bath composed of $1 \mathrm{M} \mathrm{CuSO}_{4} \cdot 5 \mathrm{H}_{2} \mathrm{O}$ and $0.4 \mathrm{M} \mathrm{H}_{2} \mathrm{SO}_{4}$. To study the effects of additives on copper deposition, various amounts of hydrochloric acid were used.

The copper electroplating was conducted at $50 \frac{\mathrm{mA}}{\mathrm{cm}^{2}}, 25^{\circ} \mathrm{C}$. Copper plates of $10 \mathrm{~mm} \times 20 \mathrm{~mm} \times 0.8 \mathrm{~mm}$ area were used as anode and cathode. The distance between electrodes was maintained at $3 \mathrm{~cm}$ throughout the process. The approximate dimensions of the substrates were prior to the electrodeposition which were ground by using 1000, 1500, 2000, 3000, 5000 grades silicon carbide papers. The surfaces of cathodes were activated in $10 \%$ sulfuric acid solution. The morphological changes on the electrodeposited copper film surface were characterized by atomic force microscopy (AFM; modelDS-95-50Ecompany name DME) in Sistan and Bluchestan University. Fig. 1 shows the AFM image of copper substrate surface preparation carried out for the plating operations. Table. 1 summarizes the relationship between different plating with the addition of chloride ions compared with those values without additives and copper film properties, such as Sy: The $\mathrm{Z}$ value range in the specified area, $\mathrm{Sz}$ : The range from the mean height of the 5 tallest summits to the mean depth of the 5 deepest valleys, Sa: The mean of the deviation from the area mean $\mathrm{Z}$ value, Sq: A measure of the dispersion of the data from the area mean, Sku: A measure of the spread of the height distribution, Sdr: This is the increase in surface area in relation to a flat surface covering the same area in the $\mathrm{X} / \mathrm{Y}$ plane, Sds: The number of summits pr. unit area, and grain size.

An ultra-low Nano scale substrates surface morphology with a root mean square deviation of around $9.88 \mathrm{~nm}$ was obtained and sdr. Shows that the surface roughness was the lowest (table. 1).
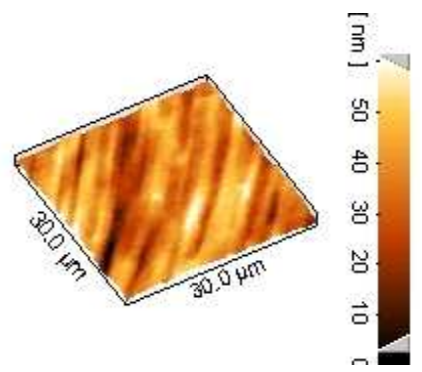

Fig. 1. The AFM $3 D$ image $\left(30 \mu_{m} \times 30 \mu m\right)$ of copper substrate surface preparation carried out for the plating operations.

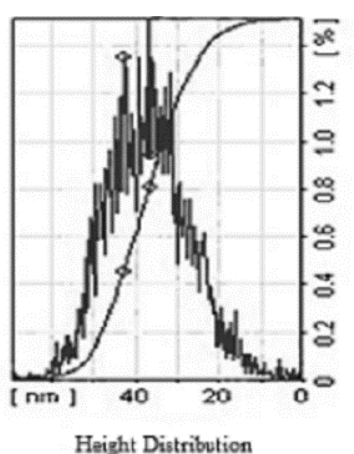

Fig. 2. surface roughness frequency curve versus height distribution was prepared for the copper substrate.

Table 1. The parameters of surface roughness for a copper substrate

\begin{tabular}{lllllll}
\hline $\begin{array}{l}\boldsymbol{S}_{\boldsymbol{y}} \\
(\mathrm{nm})\end{array}$ & $\begin{array}{l}\boldsymbol{S}_{\boldsymbol{z}} \\
(\mathrm{nm})\end{array}$ & $\begin{array}{l}\boldsymbol{S}_{\boldsymbol{a}} \\
(\mathrm{nm})\end{array}$ & $\begin{array}{l}\boldsymbol{S}_{\boldsymbol{q}} \\
(\mathrm{nm})\end{array}$ & $\boldsymbol{S k u}$ & $\begin{array}{l}S d r \\
(\%)\end{array}$ & $\begin{array}{l}S d s \\
\left.\mathbf{m m}^{-\mathbf{2}}\right)\end{array}$ \\
\hline 69.3 & 57.9 & 7.92 & 9.88 & 3.03 & 0.015 & 208889 \\
\hline
\end{tabular}

\section{Results and Discussion}

It is well known that AFM is one of effective ways for the surface analysis due to its high resolution and powerful analysis software. Figure 3 shows AFM images of the 
copper film.

The surface morphology varied according to the seed layers, and there were differences in grain size and surface roughness. The chloride ions $(0.01 \mathrm{ml})$ were added in the form of $\mathrm{HCl}$ was observed as large particles on the surface, which affected the surface morphology of the deposited copper.
(B)

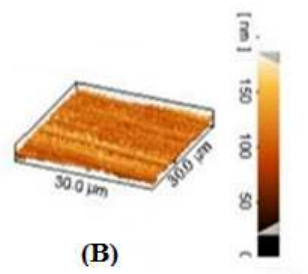

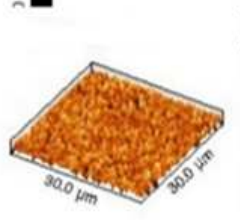

(C)

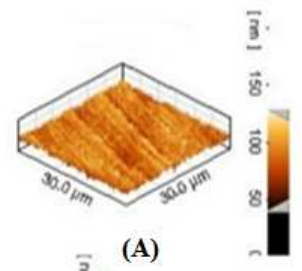

(A)

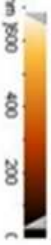

Fig. 3. The AFM $3 D$ images of deposits produced by DC plating at $50 \frac{\mathrm{mA}}{m^{2}}$ in $1 \mathrm{M} \mathrm{CuSO}_{4} 5 \mathrm{H}_{2} \mathrm{O}$ and $0.4 \mathrm{M} \mathrm{H}_{2} \mathrm{SO}_{4}$ solutions containing (A) no additive, (B) $0.001 \mathrm{ml} \mathrm{HCl}$ and (C) $0.01 \mathrm{ml} \mathrm{HCl}(30 \mu \mathrm{m} \times 30 \mu \mathrm{m})$.

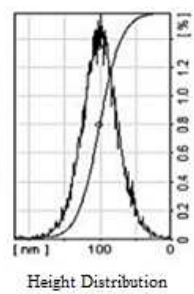

(B)

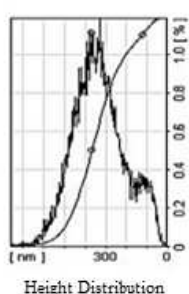

(C)

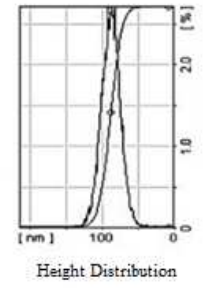

(A)
Fig. 4. The frequency distribution curves of surface roughness in terms of height, (a) without acid chloride, (b) $0.001 \mathrm{ml}$,(c) $0.01 \mathrm{ml}$ acid chloride.

Table. 2 and Figer.4 showed that the surface roughness of copper films was increased with the addition of chloride ions up to the amount of $0.01 \mathrm{ml}$. The overall copper film of root mean square deviation was increased with the addition of chloride ions compared with those values without additives. The copper film of root mean square deviation values were not significantly changed and the grain size of copper film was decreased with the addition of chloride ions up to the amount of $0.001 \mathrm{ml}$ compared with those values without additives. However, the amount of chloride ions was increased over $0.01 \mathrm{ml}$, the copper film of root mean square deviation values was increased (126nm).

As the plating with the increasing of chloride ions up to the amount of $0.01 \mathrm{ml}$, the sdr and grain size of copper films were increased.

Table 2. Represents the surface roughness parameters, the effect of addition of chloride to the copper plating solution.

\begin{tabular}{|c|c|c|c|c|c|c|c|c|}
\hline sample & $\begin{array}{l}\boldsymbol{S}_{y} \\
(\mathrm{~nm})\end{array}$ & $\begin{array}{l}S_{\mathrm{g}} \\
(\mathrm{nm})\end{array}$ & $\begin{array}{l}S_{\epsilon} \\
(\mathrm{nm})\end{array}$ & $\begin{array}{l}\boldsymbol{S}_{q} \\
(\mathbf{n m})\end{array}$ & Slku & $\begin{array}{l}\text { Sdr } \\
(\%)\end{array}$ & $\begin{array}{l}\text { Sds } \\
\mathrm{mm}^{-2}\end{array}$ & $\begin{array}{l}\text { Average } \\
\text { grain } \\
\text { size } \\
(\mathbf{A F M}) \\
\end{array}$ \\
\hline $\mathrm{A}$ & 214 & 139 & 10.5 & 13.3 & 4.22 & 0.37 & $1.71 \times$ & $\mathrm{nm} 300.89$ \\
\hline B & 220 & 203 & 20.6 & 26.3 & 3.30 & 1.44 & $1.70 \times$ & $227.935 \mathrm{~nm}$ \\
\hline $\mathrm{C}$ & 759 & 722 & 101 & 126 & 2.68 & 20.2 & 938889 & $0.925^{\mu m}$ \\
\hline
\end{tabular}

\section{Conclusions}

In this study, copper films were deposited on copper substrate using an electroplating technique with additives such as chloride ions. These results suggested that the surface roughness of copper deposit could be controlled by the amount of chloride ions. As the plating by increasing the chloride ions up to the amount of $0.01 \mathrm{ml}$, the grain size of copper films and surface area in relation to a flat surface cover the same area in the $\mathrm{X} / \mathrm{Y}$ plane increased. The influence of plating mode and chloride ion on morphology of copper deposits has been studied on pure copper substrate and the surface morphology varied according to the seed layers, and there were differences in grain size and surface roughness.

\section{References}

[1] Tae-Gyu Woo, Il-Song Park, and Kyeong-Won Seol, Effects of Various Metal Seed Layers on the Surface Morphology and Structural Composition of the Electroplated Copper Layer, Met. Mater. Int., Vol. 15, No. 2 (2009), pp. 293 297.

[2] Tae-Gyu Woo, Il-Song Park, Hyun-Woo Lee, Cheul-Ro Lee and Kyeong-Won Seol, The Effect of Hydroxy Ethyl Cellulose (HEC) and Chloride Ions on the Surface Morphology and Mechanical Characteristics during Copper Electrodeposition, Materials Transactions, Vol. 48, No. 7 (2007) pp. 1913 to 1918.

[3] Kondo. K, Akolkar. R. N, Barkey. D. P, Masayuki Yokoi, copper Electrodeposition for Nanofabrication of Electronics Devices, Chapter. 2, (2014) pp. 27 to 43, ISBN: 978-14614-9175-0.

[4] NisitTantavichet, Mark D. Pritzker, Effect of plating mode, thiourea and chloride on the morphology of copper deposits produced in acidic sulphate solutions, Electrochimica Acta 50 (2005) 1849-1861.

[5] Y. L. Kao, K. C. Li, G. C. Tu, and C. A. Huang, Microstructural Study of the Effect of Chloride Ion on Electroplating of Copper in Cupric Sulfate-Sulfuric Acid Bath, Journal of The Electrochemical Society, 152 (9) C605C611 (2005).

[6] G. Fabricius and G. Sundholm, J. Appl. Electrochem., 15, 797 (1985).

[7] A. Sato and R. Barauskas, Metal Finishing, 64th Guidebook and Directory Issue, 94 (1A), 214 (1996). 
[8] Schlesinger, M., Modern Electroplating, John Wiley, chapter 2, 5th Edition, 2000

[9] Kim, J.-H., Kim, R.-H., Kwon, H.-S., Preparation of copper foam with 3-dimensionally interconnected spherical pore network by electrodeposition, Communications 2008, 10, 1148-1151.
[10] Nader Jalili, Karthik Laxminarayana, A review of atomic force microscopy imaging systems: application to the molecular metrology and biological sciences, Mechatronics 14 (2004) 907-945.

[11] CHERYL R. BLANCHARD, Atomic Force Microscopy, Vol. 1, No. 5, I SSN 1430 - 4171 , (C) 1996 SPRINGERVERLAG NEW YORK, INC. 